\title{
Los proyectos de ordenanzas generales de médicos, cirujanos y boticarios de Castilla (ca. 1491-1513)
}

\author{
José Damián González Arce (*) \\ (*) Profesor Titular del Departamento de Economía Aplicada, Área de Historia e Instituciones \\ Económicas. Facultad de Economía y Empresa. Universidad de Murcia. josedam@um.es
}

Dynamis

[0211-9536] 2011; 31 (1): 207-226
Fecha de recepción: 17 de febrero de 2009

Fecha de aceptación: 16 de marzo de 2010

SUMARIO: 1.-Introducción. 2.-Los proyectos de finales del siglo XV. 3.-Las ordenanzas de comienzos del XVI. 4.-Documentos.

RESUMEN: Entre 1491, aproximadamente, y 1513 fueron redactados tres proyectos de ordenanzas generales con los que regular los oficios sanitarios castellanos: médicos, cirujanos y boticarios. Ninguno fue finalmente promulgado, debido a las diferencias surgidas entre los protomédicos, alcaldes mayores con competencias exclusivas sobre dichos oficios, y el Consejo Real, órgano supremo de gobernación y justicia de la Corona de Castilla, que fueron los protagonistas de la redacción de los citados proyectos. Consecuentemente, no se pudieron uniformar para todo el reino las actividades sanitarias, y los protomédicos siguieron regulando de forma unilateral y descoordinada las mismas a nivel local.

PALABRAS CLAVE: Ordenanzas, oficios sanitarios, protomédicos, Consejo Real, Castilla.

KEY WORDS: Ordinances, health professions, chief physician, the Royal Council, Castile.

\section{Introducción}

Los Reyes Católicos y Juana I emitieron ordenanzas generales para regular en la Corona de Castilla los oficios de mayor importancia. Estos procesos normativos fueron desarrollados por el Consejo Real, una suerte de consejo de ministros y tribunal supremo, que contó con asesoramiento de expertos de las diferentes profesiones. En el caso de las sanitarias, lo fueron los alcaldes y examinadores mayores, generalmente médicos reales, luego conocidos como protomédicos. Que se tratase de profesionales muy cualificados y especializados, con jurisdicción exclusiva en sus alcaldías, y con gran 
poder y autonomía, dificultó que llegasen a acuerdos con el Consejo Real y aun entre ellos mismos. De manera que, a diferencia de otras, como las textiles ${ }^{1}$, las ordenanzas sanitarias quedaron en un proyecto y no entraron en vigor; lo que habría supuesto el recorte, o al menos la regulación, de la casi omnímoda capacidad individual de los alcaldes mayores.

A pesar de no haber sido promulgada, se trata una documentación de la mayor importancia, pues nos aporta información fundamental para el conocimiento de la sanidad en la Castilla de la transición de la Edad Media a la Moderna. En efecto, nos permite observar cómo entendían las máximas autoridades políticas, Consejo Real, y médicas, alcaldes mayores, que debía regularse la misma, tras partir del análisis de su estado y de los problemas que la aquejaban, para luego proponer las soluciones a arbitrar.

En este trabajo me voy a ocupar de analizar quiénes pudieron ser los autores de los tres proyectos anónimos de ordenanzas generales aparecidos en el citado período así como cuál fue su proceso de elaboración y las dificultades a las que se hubo de enfrentar. Finalmente, editaré el tercero de estos proyectos, el más importante y el único no publicado, aunque los otros dos anteriores lo fueron en una fecha tan lejana y en una edición tan poco accesible que apenas han sido citados por los especialistas.

No queda claro cuándo fue institucionalizado el Protomedicato de Castilla como tribunal formado por los médicos reales, protomédicos o alcaldes y examinadores mayores; único con jurisdicción para entender en las causas judiciales relativas a los oficios sanitarios; con competencias para reconocer la suficiencia de quienes aspiraban a ser médicos, cirujanos y boticarios, a los que concedía las licencias necesarias para el ejercicio de dichas profesiones; y que hacía de cuerpo consultivo. Para algunos autores funcionó como tal con Juan II de Castilla, otros ven su fundación en la pragmática de 1477 mediante la cual los Reyes Católicos nombraron nuevos protomédicos, mientras que los hay que atribuyen su verdadero origen a Felipe $\mathrm{II}^{2}$. Lo cierto es que los alcaldes y examinadores mayores actuaron

1. González Arce, José Damián. La organización de la producción textil y las corporaciones gremiales en las ordenanzas generales de paños castellanas (1494-1511). Anuario de Estudios Medievales. 2008; 38 (2): 707-759.

2. Más adelante veremos unas ordenanzas de 1502 sobre los cirujanos de Toledo en las que se contiene la primera referencia documental a los «protomédicos» (protofysycos). Este apelativo ha causado una controversia más bien estéril, pues, aunque dicha denominación no apareció hasta el siglo XVI, en cualquier caso las funciones básicas de los alcaldes del siglo XV eran las mismas que las de los protomédicos del XVI. Campos Díez, María Soledad. El Real 
más como órganos unipersonales con autonomía entre ellos, y por tanto con criterio diferenciado, que como un órgano colegiado, que es precisamente lo que los Reyes Católicos quisieron conseguir con la pragmática de $1477^{3}$, si bien ésta no llegó a materializarse.

Esta autonomía llevó a los protomédicos a entender su magistratura vitalicia como un patrimonio personal que les capacitaba para delegar sus funciones en personas de su elección, incluso a través de la venta de estas lugartenencias; lo que hubo de ser prohibido por los monarcas, debido a la corrupción a que abocaban estas prácticas. Asimismo, actuaron allí donde acudían según su propio criterio, sin consultar con sus colegas, en asuntos tales como la emisión de normativas locales, la realización de exámenes o la inspección de boticas. Precisamente, otra causa del fracaso de la legislación sanitaria fueron las disensiones técnicas entre los protomédicos, sobre todo las disparidades acerca de las autoridades médicas que debían tenerse en cuenta en la confección de las medicinas o en el empleo de los sistemas métricos, como veremos.

Antes de ocuparme de los proyectos legislativos, expondré quiénes fueron los médicos que desempeñaron las alcaldías mayores durante el período de su redacción, y se convirtieron, por tanto, en los protagonistas de la misma.

En diciembre de 1474 los Reyes Católicos confirmaron al licenciado Juan de Guadalupe, nombrado por Enrique IV, como alcalde y examinador mayor de todos los físicos, cirujanos, ensalmadores, algebristas o componedores de huesos, boticarios, especieros, herbolarios y enfermos de lepra. De los primeros, médicos y cirujanos, debía recibir como derechos de examen 1 marco de plata o 5 doblas de oro, de los restantes, 3; también tendría potestad judicial. En abril de 1475 designaron junto al anterior al doctor Juan Tején, como alcalde mayor de todas las especialidades sanitarias humanas, tanto hombres como mujeres, cristianos, judíos o musulmanes. Meses más tarde, en julio, lo hacían con el doctor Juan Rodríguez de Toledo,

Tribunal del Protomedicato castellano (siglos XIV-XIX). Cuenca: Ediciones de la Universidad de Castilla-La Mancha; 1999, p. 31-36.

3. Campos Díez, María Soledad. El Protomedicato en la administración central de la Monarquía Hispánica. Dynamis. 1996; 16: 45. 
catedrático en Valladolid; quien ya había sido nombrado alcalde mayor por el usurpador príncipe Alfonso ${ }^{4}$.

En 1477 emitieron la pragmática considerada por algunos como la ley básica del Tribunal del Real Protomedicato, mediante la cual ratificaron a Rodríguez de Toledo y a Tején como alcaldes mayores, para que ejerciesen el puesto, in solidum, junto al también doctor en medicina Lorenzo Badoz y a maestre Juan de Guadalupe, todos ellos físicos de los soberanos. En adelante, los componentes de este tribunal fueron renovados conforme se producían vacantes. En una fecha indeterminada formó parte del mismo el doctor maestre Juan de Ribasaltas. En marzo de 1490, éste fue comisionado por los monarcas, junto a Rodríguez de Toledo y Guadalupe, para actuar como «nuestros alcaldes juezes por nos dados» en el caso de un boticario cordobés, Luciano Genovés, que había sido multado por un alcalde local con 10.000 maravedíes. Genovés, que había sido acusado de tener medicinas falsas y no perfectas, apeló esta sentencia ante los protomédicos, y éstos determinaron que dicha causa no debía ser atendida por el citado alcalde de Córdoba, pues el proceso debía seguirse ante ellos, lo que el concejo se negó a cumplir. En julio de ese año les encargaron determinar si varias personas estaban afectadas de lepra. En 1491, tras ser quemado en la hoguera por la Inquisición Ribasaltas, los monarcas nombraron como protomédico al doctor Nicolás de Soto, físico del príncipe Juan; mientras que en 1494 lo hacían con Gabriel Álvarez Abarca, catedrático de Salamanca, en sustitución del fallecido Juan de Guadalupe. Badoz y Ribasaltas procedían de la Corona de Aragón, llegaron a Castilla con el rey Fernando, a cuyo círculo pertenecían. Ambos eran judíos y, como hemos visto, el primero fue quemado en 1491, mientras que la viuda del segundo lo había sido en 1488. Los dos disponían del más alto título académico, «mestre en arts i medicina» y gozaron del título de protomedicus: de hecho fueron los únicos que en el siglo XV lo usaron en la Corona de Castilla, donde sólo se generalizó, por influencia aragonesa, en el siglo XVI. Ello ha llevado a

4. En enero de 1475 también nombraron al doctor Abraham Xarafi, médico del arzobispo de Toledo, como alcalde mayor de los médicos y cirujanos mudéjares, no de los boticarios, pues les estaba prohibido ejercer de tales desde el reinado de Juan II. Campos Díez, n. 2, p. 29-31. En 1476 el alcalde Rodríguez de Toledo formó parte de una comisión encargada de examinar a tres presuntos leprosos. Véase Gómez Mampaso, Valentina. Los alcaldes examinadores mayores. Origen y competencia. Boletín de la Real Academia de la Historia. 1983; 180 (3): 557. 
algunos autores a negar la existencia del Tribunal del Protomedicato en la Castilla medieval ${ }^{5}$.

En 1494 los monarcas se dirigieron a los alcaldes Rodríguez de Toledo, Soto y Álvarez Abarca para comunicarles que consideraban fraudulenta y contraria a su servicio la existencia de lugartenencias, pues su voluntad era que los exámenes fuesen realizados por los alcaldes mayores en persona, por lo que serían revocados cualesquiera nombramientos hechos por los mismos. En 1498 reiteraron la revocación y confirmaron como alcaldes mayores al citado Soto, al licenciado Alonso Fernández de Guadalupe, que previamente también había trabajado para el príncipe Juan, fallecido el año anterior, al que en febrero dieron una regiduría en Salamanca, y al doctor Julián Gutiérrez, autor del libro Cura de la piedra y del dolor de ijada y cólico renal, al que ese año el Consejo Real facultó para imprimir en exclusiva. Álvarez Abarca habría muerto antes del 4 de agosto de 1497, mientras que Fernández de Guadalupe lo haría en los primeros meses de 1498, ya que en mayo de ese año sus familiares solicitaron el reparto de su herencia ${ }^{6}$.

Por esas fechas entraron a formar parte del protomedicato otros dos médicos reales, Fernando Álvarez de la Reina y Juan de la Parra, por lo que éste volvió a estar compuesto por cuatro miembros, los antedichos más Soto y Gutiérrez. Al primero de los recién llegados a veces se le confunde con un simple «doctor de la Reina». Entró al servicio de los Reyes Católicos en 1497, año de la muerte de su hermano, Gabriel Álvarez Abarca, también conocido como Gabriel Álvarez de la Reina, que hemos visto como protomédico hasta su deceso. Al igual que Gabriel, Fernando fue catedrático en Salamanca, al menos desde 1501; en 1502 firmó una carta junto a los protomédicos Soto y Gutiérrez, de lo que cabe inferir que ya sería uno de ellos; y en 1507 la reina Juana lo tomó a su servicio. Juan de la Parra se formó, como otros prestigiosos médicos de la época, en el monasterio de Guadalupe, habiendo sido discípulo del ya citado Juan de Guadalupe. En 1490 los Reyes Católicos lo nombraron su secretario; para ellos también

5. Campos Díez, n. 2, p. 31-36. Libro de las bulas y pragmáticas de los Reyes Católicos. Madrid: Instituto de España; edición facsímil, 1973, vol. I, fols. 151v-156r. Archivo General de Simancas (AGS), Cámara de Castilla (CC), Diversos, leg. 1, doc. 54. (AGS), Registro General del Sello (RGS), 1490-03, 181; 1490-07, 451; 1491-04, 38; 1494-04, 55. García Ballester, Luis. La búsqueda de la salud: sanadores y enfermos en la España medieval. Barcelona: Ediciones Península; 2001, p. 541-545. En 1493 Rodríguez de Toledo, Soto y Guadalupe dictaminaban en un nuevo caso de lepra. Gómez Mampaso, n. 4, p. 557-558.

6. Campos Díez, n. 2, p. 34-35. 
trabajaría como médico, aunque su nombramiento oficial como tal sería en 1504, al servicio del infante Fernando; en 1497 asistió en su enfermedad mortal al príncipe Juan, junto a sus médicos Soto y Fernández de Guadalupe; mientras que en 1506 hacía lo propio con el rey Felipe, junto a sus médicos flamencos oficiales ${ }^{7}$.

En las cartas de nombramiento de los alcaldes mayores se contienen sus cometidos, a modo de estatutos que regulaban las funciones de estos jueces y examinadores. Se trata de la única legislación que podemos tener por tal para este período. En dichas cartas se establece que éstos tuviesen poder en todo el reino para evaluar a los prácticos sanitarios, a los que, si hallaban idóneos, darían cartas de examen y aprobación, así como licencia para que practicaran sus oficios libremente, penalizando, por el contrario, a quienes los ejerciesen sin tal licencia. Asimismo, tenían la facultad de llamar a su presencia a cualesquiera profesionales, y éstos la obligación de acudir, bajo pena. Así como la de inspeccionar las tiendas y boticas de boticarios, especieros y otros que vendiesen medicinas y especias, con el fin de supervisar su bondad y estado de conservación. También debían entender en los pleitos civiles y criminales referentes a estas ocupaciones. En otra disposición se establece la exigencia de evaluar de nuevo a todos los físicos, cirujanos, boticarios y especieros, aunque ya lo estuviesen, bajo la alegación de que en el pasado se habían dado cartas de examen a personas indoctas e insuficientes. Por este cometido los examinadores debían cobrar de los médicos y cirujanos un marco de plata o cinco doblas de oro, de los boticarios, tres doblas de oro, y de los especieros, una. Ahora bien, los prácticos que fueran graduados universitarios no pagarían tasa alguna. Entre los cometidos de los protomédicos estaba igualmente el velar por que en la medicina no se usasen ensalmos, conjuros ni encantamientos. Por último, estos alcaldes eran, asimismo, los encargados de fiscalizar a los empleados de los lazaretos. Para ayudarse en todas sus labores, los protomédicos podían contar con un promotor fiscal así como con uno o varios porteros para emplazar a los profesionales, dar fe de los plazos y penas, y cobrar las penas interpuestas.

7. Alonso Cortés, Narciso. Dos médicos de los Reyes Católicos. Hispania, 1951; 11: 612-639. 


\section{Los proyectos de finales del siglo XV}

A los Reyes Católicos fue presentado un memorial bajo el título: «Las cosas en que sus altezas an de mandar probeer que tocan çerca los físicos y boticarios de sus rreynos... ${ }^{8}$, que consta de 21 cláusulas. A ellas se añadió: «Que lo vean los dotores de la reyna y dotor Soto y llamen al Consejo a platicar sobre ello», en referencia a los médicos de Isabel La Católica y del príncipe Juan (Nicolás de Soto), y al Consejo Real. De modo que lo podemos fechar entre 1491, año de la alcaldía de Soto, y 1497, año de la muerte del príncipe de Asturias, cuando aquél era su médico y no todavía de la reina. En cuanto al autor, queda claro que no pudo ser uno de los alcaldes mayores, por lo antedicho y porque en la cláusula 20 se contiene un furibundo ataque contra éstos, a quienes se acusa de ser los culpables de la existencia de boticarios idiotas que desconocían el oficio y lo ejercían tras haber obtenido licencias de ellos o de sus delegados. Además, parece, por la redacción del documento, que su autor no fue un natural de Castilla, aunque sí un español conocedor del castellano, o del aragonés. En cualquier caso se trató de un médico, no sólo por los saberes que manifiesta, sino también porque habla en primera persona del ejercicio de la medicina. Dado que pone como ejemplo a seguir el modo de proceder en Zaragoza y Valencia, debió tratarse de un galeno de la Corona de Aragón. Y, como denuncia la actuación de los alcaldes mayores, a quienes propone apartar del examen de los boticarios para devolver esta facultad a instancias locales, como entonces se procedía en la Corona de Aragón y se había procedido en la de Castilla hasta la aparición de las alcaldías mayores, debió de tratarse de un personaje de gran importancia. Por todo ello, lo más probable es que fuese uno de los médicos del rey Fernando, cuya propuesta normativa pasó a ser evaluada por los de la reina Isabel y su Consejo Real: para regular la sanidad castellana parecía algo lógico recurrir a lo actuado en Aragón, donde esta actividad se encontraba mucho más desarrollada.

Pese a la relevancia de este documento, apenas ha sido manejado someramente por algunos autores, posiblemente por hallarse transcrito en una publicación relativamente antigua y difícil de consultar ${ }^{9}$.

8. AGS, CC, Diversos, leg. 1, doc. 55.

9. Villa, Isidoro de la. Los médicos y la medicina en la época de los Reyes Católicos. Comentarios a unas Ordenanzas del siglo XV, reproducidas del Archivo de Simancas. Valladolid: Talleres Tipográficos Cuesta; Valladolid; 1938, p. 41-46. Ha sido citado por Parrilla Hermida, Miguel. 
La mayor parte del memorial va referido a la forma de elaboración de las medicinas, asunto que centró los posteriores debates entre los protomédicos y les impidió llegar a acuerdos que permitiesen la promulgación de unas ordenanzas generales; sobre todo por la disparidad de criterios sobre los antidotarios y los sistemas de medida que debían emplearse. En cuanto a los primeros, se proponían los antidotarios de Johannes Mesue y Nicolás Salernitano (Antidotarium Nicolai), el «Servidor» (Liber servitoris) de Albucasis, el tratado Quid pro quo apothecariorum, el «Saladino» (Compendium aromatorium de Saladino de Ascoli) y el «Pandectas» (Liber pandectarum medicinae) de Matteo Silvatico ${ }^{10}$.

Tras este primer proyecto de ordenanzas fue redactado un segundo, probablemente por los protomédicos y el Consejo Real, tal y como se sugería en el primero. De haber entrado en vigor, éste habría visto la luz en 1498 , por lo que se indica en un añadido posterior. Del mismo se conservan dos copias encabezadas del modo siguiente: «Estas son las ordenanças que sus altezas deven mandar ordenar çerca de los físycos e los botycarios e espeçieros etc. de sus reynos» ${ }^{11}$.

Como en aquél, en el articulado de 13 cláusulas abundan las disposiciones sobre boticarios y medicinas, de las que se citan la triaca, el mitridato, los trociscos de Tiro, el ungüento marciatón y otras semejantes. Los boticarios examinados tenían que contar con algunos de los libros vistos en las primeras ordenanzas (los de Mesué, Nicolas Salernitano, Albucasis, Serapion y Matteo Silvatico), tanto en latín como en romance. Cuando dispensaran alguna medicina purgativa o cordial, solamente debían componerla tras su prescripción por uno de los médicos con los que trabajaban, para que éste, si lo estimase oportuno, viese cómo la elaboraba. Prueba de que este proyecto fue redactado tras presentarse el primero la encontramos en una anotación marginal a esta ordenanza, en la que se sugiere que era más conveniente a este respecto la segunda ordenanza del primer proyecto acerca de la elaboración de las medicinas compuestas en presencia de los médicos y boticarios locales. Estas anotaciones marginales o glosas debie-

Apuntes históricos del Protomedicato; antecedentes y organismos herederos. Anales de la Real Academia Nacional de Medicina. 1977; 94: 480-481; y glosado por García Ballester, n. 5, p. 514-559.

10. García Ballester, n. 5, p. 604-626.

11. AGS, CC, Diversos, leg. 1, doc. 56. También transcrito por Villa, n. 9, p. 47-54 y glosado por García Ballester, n. 5. 
ron ser obra de los miembros del Consejo Real, mientras que el cuerpo del proyecto de ordenanzas habría correspondido a los protomédicos. En cuanto a las medicinas fraudulentas de los boticarios, las ordenanzas se remiten a las cartas de nombramiento de los alcaldes mayores donde se contemplaba que los sentenciasen (redactado en primera persona, «sentençiemos», lo que corrobora que fueron elaboradas por los protomédicos) según el fuero del reino, de modo que los condenados debían perder la mitad de sus bienes y ser desterrados a una isla. Sin embargo, este derecho no era acorde con la costumbre de los anteriores alcaldes mayores de los físicos, que nunca por él juzgaron. En consecuencia, los protofísicos de los Reyes Católicos encontraron unas ordenanzas de los citados alcaldes mayores precedentes, según las cuales los boticarios debían ser multados con 3.000 maravedíes por la primera vez que elaborasen medicinas fraudulentas y la misma cantidad, o mayor, por la segunda, así como la quema pública de las mismas; y los monarcas debían aclarar qué derecho se debía aplicar, para que los protomédicos diesen cuenta a Dios y a los soberanos. En una anotación marginal los del Consejo insistieron en que si el delito era grave no sería inapropiada la pena del destierro y pérdida de la mitad de los bienes, siempre que se estipulara qué fraude era merecedor de esta sanción. A continuación, los protomédicos se refieren en este proyecto a cómo habían sido revocadas las lugartenencias, lo que tuvo lugar en 1494, según vimos.

Una ordenanza posterior dispone que todos los físicos, cirujanos y boticarios examinados por los sustitutos (lugartenientes) debieran serlo de nuevo en el plazo de un año por los alcaldes mayores en persona, que percibirían sus derechos. En una primera nota marginal de un miembro del Consejo se apuntó que a los que se encontrase hábiles sería conveniente no cobrarles nada o muy poco, pero los que no lo fuesen, «en pena de aver procurado la facultad que non meresçen, a estos cargaría yo la pagar». En otra anotación marginal se dice: «No sé por qué no se hesaminan los examinados por los físycos alcalldes mayores, qué verguença es lo que çerca desto pasa por ellos, y ellos con razón deverían de pagar la pena». Los reyes debían ver los capítulos del proyecto de ordenanzas y las normativas de las cartas de nombramiento de las alcaldías mayores, y lo que estimasen conveniente debían mandarlo ejecutar a los protomédicos, dándoles una carta de favor válida ante todas las justicias del reino, para que ellos pudiesen juzgar y sentenciar con arreglo a dichas ordenanzas. Luego se dice que debían añadirse las cláusulas del otro memorial (primer proyecto de 
ordenanzas) que fuesen buenas, quedando siempre por encima la superioridad de los alcaldes mayores. Las sanciones a imponer habían de ser graves, y en algunos casos de suspensión o privación del oficio y hasta de destierro, para que no fuesen todas pecuniarias; tampoco se podría cobrar el dinero sin que fuese ejecutada la otra parte de la pena.

\section{Las ordenanzas de comienzos del XVI}

El 3 de septiembre de 1502, aprovechando la estancia de la corte en Toledo (la reina Isabel con su Consejo), los protomédicos Soto y Gutiérrez hicieron leer en presencia de varios cirujanos locales (maestre Juan Serrano el viejo, maestre Juan Serrano el mozo, el bachiller Tomás de Santo Domingo, maestre García de la Torre, maestre Diego, maestre Juan de León, Juan de Soto y maestre Andrés), unas ordenanzas de ocho cláusulas ${ }^{12}$.

La primera disponía que ningún cirujano curase llagas peligrosas sin la presencia de otro cirujano acompañante. Si a éstas sobrevenían accidentes malos o se temía que así fuese, además de los anteriores, debía estar presente un médico. Si los pacientes solicitaban únicamente un cirujano, éste no podría curarle sin los otros dos; si lo hacían por carecer de recursos, solamente deberían abonar los honorarios de uno, que se repartirían entre los tres. Por el contrario, si además de los dos iniciales el enfermo quería llamar a más, el tercero habría de ser un médico, pudiendo el cuarto y los siguientes ser también cirujanos. En caso de llagados en que se esperase daño o peligro a un tercero, al haber resultado heridos intencionadamente por él, el cirujano, tras haberles comprobado la sangre, no podía curarlos sin la presencia de otro acompañante y de un médico; si demandasen más profesionales, tanto el paciente, como sus familiares o el agresor, podrían estar presentes cuantos quisiesen, tanto físicos como cirujanos. Como en el caso de las llagas, los cirujanos tampoco podían curar apostemas peligrosos en solitario, sin un acompañante, al menos hasta que dejasen de serlo; del mismo modo, si al apostema sobrevenían accidentes malos, para su cura debían llamar a un médico sabio que les aconsejase; en caso de falta de recursos por parte del paciente, se actuaría como con las llagas. 
Tras ser leídas ante varios testigos, entre los que se encontraba Rodrigo de Lunar, barbero de la reina y alcalde mayor de ese oficio, los protomédicos mandaron a los cirujanos, en nombre de la misma, la observancia de estas ordenanzas, bajo pena de 30.000 maravedíes; y quienes se sintieran agraviados por ellas, podían apelar ante los monarcas o su Consejo. Los cirujanos toledanos pidieron copia de las mismas, para hacer alegaciones. Cuatro días después el protomédico Gutiérrez hizo leer a Juan Serrano el viejo la citada normativa y le ordenó su cumplimiento; a lo que el toledano contestó que apelaba estas ordenanzas. Por el contrario, el bachiller Santo Domingo y los maestres de la Torre y de León dijeron que las acataban. Luego Gutiérrez procedió de igual forma con Serrano el mozo, que también recurrió contra las ordenanzas.

Días después, el 9 de septiembre de ese mismo año 1502, los Serrano apelaron ante la reina las ordenanzas, para lo que arguyeron que tales disposiciones eran injustas, dificultosas y oscuras en perjuicio de los enfermos, así como contrarias a derecho. Alegaban, entre otras razones, que no se había especificado qué apostemas o llagas eran las peligrosas, máxime cuando muchas no lo eran al principio aunque luego pudieran volverse de tal tenor; además, con tantos profesionales se perdería mucho tiempo en ponerse de acuerdo sobre el tratamiento; otro inconveniente derivaría de reunirlos, sobre todo en los pueblos pequeños y aldeas, lo que llevaría a desperdiciar un tiempo precioso para la curación. Además, argumentaban que muchos de los cirujanos dados por examinados por los protomédicos habían sido privados de sus cartas de examen al no ser luego encontrados hábiles, de forma que quienes las tenían debían ser considerados capaces de curar en solitario, y si no lo hacían correctamente, que fuesen sancionados. En esta apelación los Serrano se refieren a los alcaldes mayores como «protofysycos e alcalldes de vuestra alteza». Aunque el prefijo «proto» fue añadido arriba, interlineado, se trata de la primera cita conocida del semema «protomédico».

Estas ordenanzas toledanas son un buen ejemplo de la capacidad normativa de la que gozaban los alcaldes mayores a nivel local, quienes podían actuar a este respecto en solitario, si bien en este caso fueron rubricadas por dos de ellos (Soto y Gutiérrez). Esta circunstancia puede explicarse bien porque todavía no habían sido nombrados los nuevos protomédicos (De la Reina y De la Parra), o bien porque éstos ya estaban enfrentados a los anteriores, lo que les llevó a actuar al margen de aquéllos, impidiéndoles 
entenderse para acordar el tercer proyecto de ordenanzas generales que ahora veremos.

Dicho proyecto se inició hacia $1510^{13}$. La reina Juana había sido informada de que «muchos médicos e çerujanos» ejercían la medicina sin haber estudiado el tiempo preciso o sin ser examinados, y de que los boticarios tampoco practicaban sus oficios ni elaboraban las medicinas como debían; motivos por los que ordenó «a los del mi Consejo y a los protomédicos» que proveyesen al respecto. Éstos, tras consultar con varios médicos y cirujanos, redactaron unas ordenanzas que regulaban los tres oficios (documento 2), posteriormente aprobadas, en principio, por la soberana, para lo que se emitió un borrador de carta real a este respecto (documento 1); aunque no nos consta que fuesen efectivamente promulgadas, pues dicha carta carece de las disposiciones finales, como la iussio, data, escribanos, etc.

Se trata de un cuerpo de 23 capítulos que algo recogen de lo contenido en los proyectos anteriores, más bien memoriales. Ahora bien, a diferencia de éstos, su estructura es plenamente la de unas ordenanzas, pues cada artículo consta de la parte dispositiva («mando» $\mathrm{u}$ «ordeno», por parte de la reina, en primera persona) y de las sanciones previstas por su incumplimiento, algunas de ellas añadidas al margen del texto. Sin embargo, no es una normativa del todo acabada, porque carece del preámbulo, con la intitulación, la exposición de motivos y la data, así como de la parte final, con sus disposiciones últimas, la iussio, los escribanos, la testificatio, la validatio, la firma real y la mención al sello de plomo autentificador; de manera que de nuevo estaríamos ante un proyecto que contendría solamente la parte dispositiva, articulado o texto de las ordenanzas, que no habría entrado en vigor ${ }^{14}$. El mismo fue elaborado por los «médicos» (protomédicos), el licenciado Polanco, miembro del Consejo Real, y el escribano Castañeda.

La ordenanza decimonovena aparece tachada, y se lee en el margen: «esta ordenança no se escriba porque se a de mirar más». En ella se dispone que los boticarios estaban obligados «a pesar verdadera y justamente, en pesos ajustados por determinación de los médicos, las onzas y adarmes de las aguas y medicinas que los mismos les encargasen»; de lo contrario caerían

13. AGS, Consejo Real de Castilla, leg. 51, fol. 11. Citado por Campos Díez, n. 2, p. 47-49, a partir de otro documento, AGS, CC, Memoriales, médicos, 106, 8.

14. González Arce, José Damián. Documentos medievales de Sevilla en el Archivo Municipal de Murcia. Fueros, Privilegios, Ordenanzas, Cartas, Aranceles (siglos XIII-XV). Sevilla: Ayuntamiento de Sevilla; 2003, p. 67-68. 
en las penas en las que incurrían los que pesaban con medidas falsas. Ello nos permite encontrar sentido al resto de los documentos contenidos junto a este proyecto de ordenanzas. Se trata de una serie de respuestas dadas hacia 1513 de forma conjunta por «el dotor Julián Gutiérrez, protomédico de vuestra alteza», a dos solicitudes del Consejo Real. Una, para que opinase sobre estas ordenanzas, que le fueron remitidas por dicho Consejo hacia 1510 , y la otra posterior, para que lo hiciese, junto a los restantes protomédicos, a cuatro cuestiones sobre pesas medicinales. En estas respuestas se informa de las controversias surgidas a este respecto entre los protomédicos, sobre todo entre Gutiérrez, por un lado, y De la Reina y De la Parra, por otro, mientras que Soto habría permanecido neutral, lo que impidió el consenso sobre el proyecto de ordenanzas generales y su promulgación.

\section{Documentos}

\section{Documento 1}

¿1510-1513? Borrador de carta real, preámbulo y parte final, con la que Juana I validase el proyecto de ordenanzas transcritas en el documento 2 . Archivo General de Simancas, Consejo Real de Castilla, legajo 51, folio $11^{15}$.

Doña Juana etc. Por quanto he sydo ynformada que a causa que muchos médicos y çerujanos de los mys reynos e señoríos se entremeten a curar de física y çerujía syn aver estudiado el tienpo que es nesçesario y otros syn ser esaminados, y que asymismo los boticarios destos mis reynos no usan de sus ofiçios ni hazen las mediçinas como deven, muchas personas an reçebido mucho dano u otros an peligrado de muerte y se han recreçido otros muchos daños e ynconvinientes de que mis suditos y naturales reçiben mucho perjuisio, y porque a mí, como a reyna e señora zeladora del bien y pro común destos mis reynos y de mis sudictos dellos en lo tal perteneçe proveer e remediar, mandé a los del mi Consejo y a los protomédicos de mi corte que viesen y platicasen lo que convenía de se proveer y remediar çerca de lo susodicho, porque los dichos ynconvinientes çesasen e no pasase más adelante, los quales después de bien visto e platicado lo que les paresció que convenía de se proueer, e asymismo aviendo oydo sobre ello otros muchos físicos y çerujanos

15. Los corchetes y los paréntesis han sido introducidos en la transcripción; los primeros, para numerar las cláusulas de las ordenanzas e indicar los añadidos al texto, tanto en los márgenes laterales, como entre líneas o al final del mismo. 
[famosos $]^{16}$ destos mis reynos fesieron e ordenaron çiertas hordenanças que disponen la forma e orden que los dichos físicos, e çerujanos e boticarios an de tener así çerca de la forma de sus exámenes, como del tienpo en que an de estudiar y en el harte de las dichas medeçinas, e sobre otras cosas en las dichas ordenanças contenidas. Su tenor de las quales es este que se sygue:

E fue acordado que devíamos dar esta mi carta en la dicha rasón. E yo tóvelo por bien, e por esta mi carta confirmo e apruevo las dichas ordenanças que de suso van incorporadas, e mando a los del mi Qonsejo, [al presidente] ${ }^{17}$, e oydores de las mis audiençias e a los alcalldes de la mi casa, e corte, e chancillerías e a todos los corregidores, asistentes, alcalldes, escribanos, justicias e jueses quealesquier de todas las çibdades, e villas e logares destos mis reynos e señoríos, e a los mis protomédicos, e alcalldes examinadores, e a los físycos, e çirujanos, e botycarios e a todas las otras personas a quien toca e atañe lo que en las dichas ordenanças [e a cada uno dellos] ${ }^{18}$ qontenido que en tanto mi merçed e voluntad guarden, e cunplan las dichas ordenanças que de suso van yncorporadas, e que contra el thenor e forma de lo en ellas qontenido non vayan, ni pasen ni consientan yr ni pasar, agora ni de aquí delante, ni nigund tienpo ni por alguna manera, so las penas en las dichas ordenanças qontenidas. Las quales mando [a vos $]^{19}$ las dichas mis justicias e a cada uno [en vuestros $]^{20}$ lugares e juridiçiones que executéis e fagáis executar en las personas de los que contra ello fueren o pasaren. E porque lo susodicho sea público e notorio a todos e ninguno dello pueda pretender ynorançia, mando que esta mi carta sea pregonada públicamente en mi corte por pregonero e ante escribano público. E los unos ni los otros, etc.

\section{Documento 2}

¿1510-1513? Cuerpo de un proyecto de ordenanzas para regular los oficios sanitarios, redactado por los protomédicos y el Consejo Real. Archivo General de Simancas, Consejo Real de Castilla, legajo 51, folio 11.

[1] Primeramente, mando que de aquí adelante ningund físico sea osado de curar pública ni secretamente enfermedad alguna, grande ni pequeña, syn que primeramente aya estudiado a lo menos syete años en artes e medeçina en

\footnotetext{
16. Interlineado.

17. Interlineado.

18. Interlineado.

19. Interlineado.

20. Interlineado.
} 
estudio general, después de ser ynstruydo en gramática e lógica, e sea graduado a lo menos de bachiller en medeçina en el estudio que oviere cursado, y que los dichos syete años aya estudiado en cada un año ocho meses y non menos, e los dos años postreros aya platicado con físico aprovado e conoçido en el estudio general, e que en la carta del grado que le dieren dé fee el escrivano del estudio cónmo estudió el dicho tienpo; so pena que sea ynabile para poder curar e de diez mill mrs. por la primera vez, e por la segunda vez la pena doblada, e por la terçera vez sea desterrado perpetuamente destos mis reynos e señoríos; la qual dicha pena mando que se reparta en tres partes y que la una terçera parte sea para el acusador que lo acusare, y la otra terçera parte para el juez que lo sentençiare y la otra terçera parte para mi cámara e fisco.

[2] Otrosy, mando que ninguno de los mis protomédicos que tienen cargo e poder para esaminar los físicos e çirujanos non pueda dar ni dé liçençia a ningund físyco ni çirujano con condiçión, ni a çierto tienpo, ni para que cure en çierto lugar, ni permita que pueda curar de unas enfermedades y no de otras, ni mandar que físico ni çirujano alguno cure con otro físyco o çirujano aunque sea graduado o esaminado, salvo que sy viere que el físyco o çirujano que hesaminare no tyene las letras, e abilidad y espiriençia que conviene al ofiçio les proyban e bieden que no usen del ofiçio ni curen a persona alguna [salvo roturas, bubas, oculistas y otras semejantes cosas recavrares] ${ }^{21}$. Y asimismo que no den ni puedan dar lugar a boticario alguno con condiçión ni a tienpo, como dicho es en lo de los físicos e çirujanos; so pena [de (en blanco) mrs., la qual dicha pena se reparta en tres partes en la forma susodicha] $]^{22}$.

[3] Otrosy, mando a los dichos médicos e çirujanos que quando ellos vieren que convenga digan secretamente a los parientes del enfermo que se confiese y reçiba los sacramentos de la santa madre Yglesia.

[4] Otrosy, mando que ningund çirujano pueda usar ni use de física en ningund lugar donde oviere físyco aprovado, aunque los enfermos y paçientes le llamen, e dexe la cura al físyco, y el físyco al çirujano, salvo sy el paçiente quisiere llamar al físyco para que concurra con el çirujano o al çirujano para que concurra con el físyco, para quel uno al otro den su paresçer, e en caso que en el lugar no aya sy no un físyco o un çirujano mando que en tal caso el físyco siendo esaminado en çirugía pueda usar de çirugía, y el çirujano pueda curar de física, siendo hesaminado en medeçina, y no en otra manera aunque qualquier dellos sea aprovado en física solamente o en çirugía solamente; so pena que sea ynábile para [poder curar dende en adelante e de (en blanco) mrs., e la dicha pena se reparta en tres partes en la forma susodicha ${ }^{23}$.

21. Interlineado.

22. En el margen derecho.

23. En el margen derecho. 
[5] Otrosy, mando que todos los físicos hagan juramento ante las justiçias de las çibdades, e villas e lugares destos mis reynos e señoríos que cada vez que los boticarios usaren mal de sus ofiçios, o dieren medeçinas falsas, o unas medeçinas por otras, o herradas o añejas que lo notificarán a las dichas mis justicias para que lo punan e castiguen, salvo sy en el tal lugar estovieren los dichos mis protomédicos o alguno dellos, porque en tal caso se a de notificar a ellos para que lo punan e castiguen.

[6] Otrosy, mando que ningund físico ni çirujano no puedan tener ni tenga tyenda de boticario en su casa ni en otra casa alguna aunque no sea suya, ni venda medeçinas por sy ni por otra persona, salvo en el lugar donde por su pobreza no pueda aver boticario o no le aviendo en otro lugar çercano a él; so pena de [(en blanco) mrs., la qual se parta en tres partes en la forma susodicha ${ }^{24}$.

[7] Otrosy, mando que ningund físico no tenga conpañía pública ni secretamente con ningund boticario, ni paga reçiba del parte, ni ganançia, ni otra cosa alguna de ganançia, ni provecho, ni ynterese alguno, salvo que solamente pueda reçebir del dicho boticario medeçinas para curar a los de su casa y no pago otro alguno. El paçiente a quien curare el tal físico tenga libertad de enbiar la reçebta al botycario quel quisiere. So pena quel físico que lo contrario fisiere por la primera bez pague diez mill mrs. de pena [de los quales sean los tres mill dellos para los mis protomédicos e los otros mrs. restantes se hagan tres partes $]^{25}$, y sea la terçera parte para el acusador que lo acusare, y la otra terçera parte para el juez que lo sentençiare, y la otra terçera parte para mi cámara; y el boticario yncurra en la dicha pena e dende en adelante non pueda usar del ofiçio de boticario ni físico por dos años, y por la segunda vez pierdan la meytad de sus bienes e sean ynábiles perpetuamente para usar de los dichos ofiçios. E porque esto se guarde e cunpla mejor mando que todos los dichos físicos e boticarios sean obligados a jurar lo susodicho ante las mis justiçias de las çibdades, e villas e lugares destos mis reynos e señoríos donde fueren vesinos e usaren los dichos ofiçios [e que no ordenaren en casa de los dichos botycarios] ${ }^{26}$.

[8] Otrosy, mando que todos los físicos e çirujanos hagan las reçebtas que ordenaren para purgar, o para tomar xarabes o para curar qualquier enfermedad en romançe e no en latín quanto fuere posible aviendo bocablos dello en romançe, y que las dichas reçebtas bayan escriptas claramente syn las abrebiar ni poner por sumas e figuras, declarando clara e abiertamente lo que mandan que tome el enfermo y los pesos que ha de pesar, e en el comienço de la tal reçebta escriba el físico o çirujano para quién es, declarando el nonbre

\footnotetext{
24. En el margen derecho.

25. En el margen derecho.

26. En el margen derecho.
} 
del enfermo sy el paçiente no quisiere que se calle, porque no se truequen las dichas reçebtas e los botycarios no den unas medeçinas por otras.

[9] Otrosy, porque soy ynformada que se sigue mucho ynconbiniente que los barberos syn aver estudiado ni platicado en çirugía curan y exerçen el ofiçio de çirugía, mando que de aquí adelante ningund barbero sea osado de exerçer ni usar el ofiçio e arte de çirugía en ningund llaga, ni ponçoña ni ferida que sea, so pena que por el mismo echo sea pribado del dicho ofiçio de barbero, pero permito que puedan haser las primeras curas que son permitidas a los barberos.

[10] Otrosy, mando que los chripianos nuevos de judíos y moros que ovieren usado fasta aquí de los dichos ofiçios de física e çirugía que no fueren esaminados que no curen de los dichos ofiçios syn ser esaminados, y siendo esaminados mando que en tal caso puedan curar syn ser graduados syendo de los que fueron aprovados antes de su conbersión.

[11] Otrosy, mando que ningund barbero sea osado de sangrar a ningund paçiente sy no fuere esaminado y aprovado por los alcalldes mayores dellos, e que ningund barbero sea osado de enbiar otro barbero alguno a ninguna aldea ni logar a faser las dichas sangrías sy el tal barbero no fuere hesaminado, e que ninguno de los dichos barberos pueda haser las dichas sangrías syn que físico o çirujano lo mande o syn que sea çertificado que lo mandó faser el tal físico o çirujano, para que se haga conmo él lo mandó; so pena de [(en blanco) mrs., los quales se repartan en tres partes en la manera susodicha] ${ }^{27}$.

[12] Otrosy, mando que sy alguno de los mis protomédicos reprobare algún médico, o çirujano o boticario que no pueda después ser aprovado por otro médico alguno salvo por todos los dichos mis protomédicos juntos, o por la mayor parte dellos, e que quando quiera que alguno de los dichos mis protomédicos esaminare algund médico, o çirujano o boticario le pregunte si a sydo reprobado otra vez, e quel hesaminado lo confiese; so pena que sy alguno se esaminare e no descubriese sy a sydo reprovado que sea ynábile perpetuamente e pague veynte mill mrs. de pena para mi cámara, e el protomédico que le esaminare le abise de la pena en que cahe sy no descubrieren lo susodicho.

[13] Otrosy, mando que ningund boticario sea osado de tener tienda ni botica ni vender medeçinas algunas, pública ni secretamente, syn que sea esaminado por los protomédicos que desto tienen cargo.

[14] Otrosy, mando que ningund boticario no sea osado de conponer medeçina laxativa, ni enplasto famoso, ni letuario cordial de los prinçipales syn que primeramente llame al físico [esaminado o graduado] ${ }^{28}$ de la çibdad, o villa o lugar donde estoviere para platicar con él la dicha conpusiçión, e

27. En el margen derecho.

28. Interlineado. 
mando quel tal físico baya luego a ver la dicha conpusyçión quando fuere llamado por el dicho boticario para ver la dispensaçión de la dicha medeçina, e sy no lo quisiere haser quel corregidor e alcallde de la tal çibdad, villa o lugar le conpela e apremie a ello, y el boticario que de otra manera lo hisiere caya e yncurra en pena de (en blanco) mrs., la qual dicha pena se repartan en tres partes en la forma susodicha. E mando que las medeçinas que se sacaren de la tal çibdad, o villa o lugar para otros lugares sean vistas y hesaminadas por boticario hesaminado e bayan çerradas e selladas, so la dicha pena.

[15] Otrosy, mando que ningund boticario ni espeçiero sea osado de dar medeçina eçedente en grado quarto, ni medeçina ponçoñosa syn mandamiento de físico o çirujano graduado o aprovado e syn reçebta firmada del nonbre del físyco, en la qual declaren el nonbre y la persona a quien manda dar la dicha medeçina; so pena que por la primera vez pierda la meytad de sus bienes, e por la segunda vez pierda todos sus bienes e sea desterrado de mis reynos perpetuamente, la qual dicha pena sea repartida en tres partes en la forma susodicha, e sy la terçera vez cometieren lo susodicho sea avido por echo del delito e conmo a tal se dé la pena estableçida en derecho.

[16] Otrosy, mando que los boticarios sean obligados de tener libro de todos los conpuestos que hisieren, e de dar en cada medeçina conpuesta el día y el año en que se conpuso, y el antidotario por donde la hizo, y que asimismo ponga en cada basija donde estoviere la tal medeçina conpuesta el día y el año en que se conpuso, y que no las renueven en manera alguna; so pena si así no lo hisieren e no dieren el físico ante quien conpusieron las tales medeçinas que sean avidos por falsos e que la primera vez paguen dos mill mrs. de pena, e por la segunda vez paguen quatro mill mrs. e por la terçera vez pague seys mill mrs. e sea desterrado por un año de la çibdad, villa o lugar donde vibiere, la qual dicha pena se reparta en tres partes en la forma susodicha.

[17] Otrosy, mando que ningund boticario no sea osado de usar de física ni çirugía aunque diga que sabe espiriençias, las quales no pueda haser syn acuerdo firmado de nonbre de físico que sea graduado e esaminado, ny el tal boticario sea osado de dar ninguna mediçina prinçipal syn reçebta o mandamiento de físico o çirujano graduado o esaminado sy no fuere la medeçina prinçipal tan neçesaria de darse luego que fuese peligro esperar reçebta [asy conmo trata otra cosa semenjante para el que sea herido de ponçoña $]^{29}$.

[18] Otrosy, mando que ningund boticario sea osado de haser yguala ni partido en conbenençia con ningund físico porque ordene en su casa, ni darle ni prometelle cosa alguna en poca ni en mucha cantidad por rasón de lo susodicho, segund e conmo e so las penas contenidas en el capítulo desuso

29. En el margen derecho. 
declarado que habla en lo de los físicos; la qual dicha pena se reparta en tres partes en la forma susodicha.

[19] [Esta ordenança no se escriva porque se a de mirar más] ${ }^{30}$. [Otrosy, mando que los dichos boticarios sean obligados a dar y pesar verdadera e justamente por peso justado por determinaçión de físicos todas las onças e adarmes de las aguas e medeçinas que los físicos mandaren dar, e que no puedan tener pesa sy no fuere en la forma susodicha; so las penas en que cahen e yncurren los que pesan con pesas falsas e más de tres mill mrs. para la mi cámara por la primera vez, e por la segunda que pierda la meytad de sus bienes, las quales dichas penas se repartan en tres partes en la forma susodicha $]^{31}$.

[20] Otrosy, mando que en cada çibdad, villa o lugar donde oviere los dichos físicos, e çirujanos, e corregidor, o sus alcalldes e los alcalldes ordinarios de la tal çibdad, villa o lugar junten a los dichos físicos, e çirujanos e boticarios dos vezes en el año, la primera vez en el mes de desienbre y la otra vez en prinçipio del mes de julio, e en su presençia sobre juramento que primeramente hagan ante ellos los dichos botycarios del verdadero balor e preçio que les costaron las medeçinas, e trayendo estrumento sygnado del preçio verdadero a cómo las pagó, e avida consideraçión de los lugares donde se traen e de la abundançia o carestía de las dichas medeçinas, asy de las que se trageren de fuera destos mis reynos conmo de las que ay en estos mis reynos, los dichos físicos e çirujanos tasen e moderen las dichas medeçinas e todas las otras cosas que oviere en cada de los dichos boticarios para curar enfermedades, la qual dicha tasaçión hagan sobre juramento justa e moderadamente para todo aquel año, e fecha la dicha tasaçión la firmen los dichos físicos e çirujanos de sus nonbres. E que los dichos boticarios no sean osados de pedir ni llevar por las dichas medeçinas más de lo que así fuere tasado en la forma susodicha. Y porque esto se guarde mejor, mando que los dichos físicos e çirujanos sean obligados a poner la tasa en cada una de las reçebtas que dieren, conformándose con la tasa e moderaçión que tienen fecha; so pena de [(en blanco) mrs. por cada vez que contra ello fueren, la qual dicha pena se reparta en tres partes en la forma susodicha $]^{32}$.

[21] Otrosy, mando que los dichos botycarios sean obligados a tener tabla a la puerta donde venden sus medeçinas en que esté escripta la tasa que se ha echo de las medeçinas aquel año, e por qué médicos, firmada a lo menos de un médico e de la justiçia del lugar.

[22] Otrosy, mando que en la villa de Medina del Campo se haga una alhóndiga en una o dos casas o más que fueren menester para las medeçinas

30. En el margen izquierdo.

31. Tachado.

32. En el margen derecho. 
que vinieren de Poniente de espeçería, aparte de las casas que se dizen medeçinas, porque sepan todos a do se vende, e se venda a mejores preçios; e el corregidor de la dicha villa con un físico esaminado visite las medeçinas que en la dicha alhóndiga se vendieren, porque no aya lugar que allí se trayan medeçinas falsas.

[23] Otrosy, mando que el corregidor, o lugarteniente o los alcalldes de cada çibdad, o villa o lugar destos mis reynos sean obligados dos vezes al año con un físico aprovado y esaminado ver e bisitar las tiendas de los boticarios e las medeçinas que tienen, e sy en tal lugar estoviere algund protomédico lo haga e se ynforme sy se guardan estas dichas ordenanças e sy se haze alguna cosa yndevida contra ellas, para que lo castiguen conforme a lo en estas dichas ordenanças contenido.

Los médicos. El liçenciado Polanco. Castañeda. 